\title{
COMENTÁRIO A ROBERTO MOTTA
}

\section{Élide Rugai Bastos}

Eu sou trezentos, sou trezentos e cinqüenta. A frase de Mário de Andrade parece-me perfeita para descrever Gilberto Freyre. Não sei se a Mário agradaria ver aplicada a Gilberto descrição que faz de si mesmo. Também não creio que Gilberto gostasse de se ver tão bem retratado por Mário. De todo modo, parece-me que a expressão traduz a visão prismática de Roberto Motta referindo-se ao objeto de minha pesquisa no livro As criaturas de Prometeu. Correndo o risco de reduzir seu argumento, explorado no texto a partir de diversas facetas, parto do que considero a principal afirmação do autor: a multiplicidade de Freyre não pode ser captada através da perspectiva sociológica que adoto. Isto é, "há oposição diametral entre o modo gilbertiano de pensar e o paradigma de ciência social, que veio a prevalecer na Universidade de São Paulo, e que vem a difundir-se ou confundir-se com o paradigma de outras universidades, em São Paulo e noutros estados”.
Considero a provocação muito interessante, pois permite enfrentarmos uma importante polêmica para refletir sobre o pensamento social brasileiro e as ciências sociais em particular.

Declaro, antes de tudo, que me sinto honrada com o estudo minucioso que o antropólogo faz de meu livro, generosamente valorizando-o. Seu conhecimento da obra de Gilberto Freyre é reconhecido por todos. Na entrevista que fiz com Gilberto e que se encontra no final de meu livro, ele cita Roberto Motta como "realmente brilhante e com uma nítida influência minha na Antropologia, sem dúvida”.

Como o comentarista se dedica a examinar com profundidade o desenrolar de minha argumentação, para não me estender muito, passo a refletir apenas sobre alguns pontos do diálogo que empreende com ele.

Lembro que a leitura de um texto é um ato de interpretação, portanto - felizmente, pois de outro 
modo não só seria monótono, como também contribuiria para que o conhecimento permanecesse estático - varia de leitor para leitor. Isso porque, segundo Jameson, "nunca realmente abordamos um texto de imediato em todo seu frescor, como coisa-em-si mesma. Em vez disso, os textos se nos apresentam como o 'sempre-já-lido'; nós os apreendemos por meio de camadas sedimentadas de interpretações prévias, ou - se o texto é absolutamente novo - por meio de hábitos de leitura sedimentados e categorias desenvolvidas pelas tradições interpretativas de que somos herdeiros" (Jameson, 1992, pp. 9-10). Assim, concordo com a afirmação de Roberto Motta de que minha leitura tem endereço conhecido - pertenço a uma tradição interpretativa que tem sua base na Faculdade de Filosofia e Ciências Humanas da Universidade de São Paulo (aliás, não apenas no curso de Ciências Sociais da USP, como sugere), e a partir desse código interpretativo abordo parte da obra de Gilberto Freyre.

Código interpretativo é o que entendo por método e penso que, mesmo não estando um autor totalmente consciente dele, impõe-se na análise empreendida, seja ela ampla ou restrita. É o modo pelo qual abordamos um texto e nos apropriamos dele. Um método não está sozinho no campo interpretativo: ele completa, se opõe, dialoga, entra em conflito explícito ou implícito com outros métodos. A complementaridade ou a contraposição traz riqueza ao debate e contribui para ampliar o conhecimento. É isso que não faz dele $o$ método, mas um método entre outros.

Mas, vamos ao tal paradigma da ciência social uspiana.

Com acerto, Motta sugere estar na discussão do texto de Gilberto Freyre Como e porque sou e não sou sociólogo a indagação que dirige minha reflexão. Sendo há muito leitora assídua e fascinada de seus grandes livros, destacando-se Casa-grande \& senzala, contentei-me, durante muito tempo, com a apreensão "por meio de camadas sedimentadas de interpretações prévias" que os indicava como não classificáveis. Ou, segundo lembra Roberto Motta, como um mysterium tremendum et fascinosum. Por isso fiquei intrigada com a preocupação de Gilberto em definir-se - sou e não sou sociólogo - no caso, em um texto publicado 35 anos depois do lançamento de Casa-grande \& senzala, livro que o consagrou como intérprete do Brasil. Chamou-me a atenção a declaração de seu interesse pela construção de uma sociologia que caminhasse "para sua autêntica universalidade. Nunca [...] seguindo-se passivamente num país o que vem resultando válido noutro país. Foi dentro desse critério, procurando ousadamente lançar sugestões para uma nova interpretação da formação brasileira, que me empenhei em considerar sociologicamente o negro africano" (Freyre, 1968, p. 52, grifo meu).

A partir daí algumas perguntas antepuseram-se à minha reflexão. Entre as diversas perspectivas possíveis, por que a sociológica serviria para resgatar o lugar do negro africano na estrutura social brasileira, tema central de Casa-grande \& senzala? Entre os muitíssimos gilbertos, o sociólogo encontraria um lugar especial? Os outros "gilbertos" anulariam a possibilidade de vê-lo como sociólogo?

Assim, ao retomar a leitura dos livros que compõem a Introdução à história da sociedade patriarcal no Brasil, tentei buscar a teoria sociológica que serviria de fundamento à sua interpretação. É claro que não a encontrei, pois coerentemente com a frase indicada acima, Gilberto não aceitava passivamente, ao estudar a formação brasileira, as teorias delineadas para explicar a realidade social de outros países. Ele mesmo afirma uma influência múltipla, às vezes contraditória, presente em sua interpretação do Brasil. Indicando esse traço utiliza a frase de Frei Amador Arrais: "Confesso que as mais iguarias com que vos convido são alheias, mas o guisamento delas é de minha casa" (Freyre, 1957, p. 80). Em outras palavras, atribui-se uma tarefa especial que supõe originalidade teórica.

Assim, creio, a afirmação de ecletismo, que o comentarista credita a mim, é do próprio Gilberto, e eu não classificaria seus trabalhos como uma obra simplesmente eclética. Aliás, não considero o ecletismo tão simples assim; não o confundo com fraqueza teórica. O ecletismo gilbertiano, conforme suas próprias palavras, é acionado "ousadamente" em busca de uma "nova interpretação da formação brasileira". Compreendo essa frase na seguinte direção: a uma sociedade singular cabe a busca de uma interpretação original e não apenas a repetição de explicação já pronta. 
A título de curiosidade, lembro que este é um dos princípios "do paradigma de ciência social que veio a prevalecer na Universidade de São Paulo". ${ }^{1}$ Para ilustrar, tomo as palavras de Florestan Fernandes, quem delineou caminhos para a sociologia naquele curso: "Através de escolhas judiciosas, o sociólogo brasileiro pode contribuir de forma original e criadora para o enriquecimento de ramos da teoria sociológica que não podem ser cultivados com a mesma facilidade por seus colegas dos 'países desenvolvidos' do mesmo círculo civilizatório. As sociedades que se afastam do tipo 'normal', inerente a determinada civilização, representam, em si mesmas, um problema teórico para a ciência" (Fernandes, [1962] 1976, p. 19). ${ }^{2}$ O autor também atribui tarefa específica ao cientista social brasileiro, mas acrescenta a ela, na continuidade do texto acima citado, o estatuto de "missão", na mesma direção de Mannheim, pois tem como fundamento explícito um efeito político. Embora aqui resida uma diferença importante em relação às posições de Gilberto Freyre, deixo de desenvolver a questão, pois não se refere diretamente à temática proposta por Roberto Motta.

Supondo que Gilberto Freyre buscava apoio em várias fontes teóricas, tentei "compreender a arquitetura interna" de sua obra bem como "suas linhas mestras e articulações principais". Nessa busca procurei aproximar sua interpretação àquela dos ensaístas dos anos de 1920, uma vez que me parecia que todos procuravam responder à mesma pergunta: que país é este? Mais ainda, para enfrentá-la elegiam como pontos temáticos a questão da cultura e a busca da identidade nacional.

Nesse confronto pude perceber que, considerando adequadas as palavras de Roberto Motta sobre minha interpretação, no "mercado concorrencial do ensaísmo da primeira metade do século XX, Gilberto Freyre apresenta o produto melhor acabado”. Nova pergunta se colocava então: qual a razão dessa superioridade? A resposta poderia limitar-se, como já havia sido dada por vários autores, à sua inegável genialidade. Embora, sem dúvida esta qualidade seja essencial, o domínio de um novo instrumental analítico pareceu-me importante para que ele desse um grande passo na análise da realidade brasileira. O próprio Gilberto lembra a vantagem dessa situação: "Já houve quem desse como condição ideal do pesquisador sociológico ou do intérprete da realidade social - precisamente esta: o indivíduo ter sido participante íntimo e ativo da vida e dos valores do grupo e ter se afastado deles por muito tempo. No regresso - dado, é claro, que reunisse a essa vantagem as do preparo técnico - estaria singularmente apto àquela interpretação. $\mathrm{O}$ autor (não por nenhum mérito de sua parte, mas pelo favor das circunstâncias) teria voltado ao Brasil nessa condição ideal para estudá-lo e interpretá-lo, se nessa questão de método nos estudos sociais o principal não fosse, afinal, o próprio pesquisador: seu conjunto de qualidades pessoais, intelectuais e científicas" (Freyre, 1941, pp. 39-39, grifo meu). Novamente, a oposição "sou/não sou" aguçou-me a curiosidade. Gilberto afirma simultaneamente o peso de seu preparo técnico e de suas qualidades pessoais e intelectuais. Ambos aparecem como elementos fundamentais, opinião com a qual concordo. Eu sou trezentos, sou trezentos e cinqüenta...

O passo seguinte foi buscar em que medida esse preparo técnico permitiu a Gilberto dar um salto em relação aos autores que o precederam na discussão sobre a formação da sociedade brasileira. É amplamente conhecido que, entre outros, dois pontos são ressaltados como fundamentais à argumentação central de Casa-grande \& senzala: a demonstração da anticientificidade das interpretações racistas e a crítica ao determinismo geográfico. A originalidade das teses gilbertianas sobre a interpenetração de etnias/culturas e sobre o papel do trópico na configuração das relações sociais no Brasil fundamenta-se nessa afirmações. ${ }^{3}$ Como sabemos, essa interpretação altera o rumo do debate sobre as relações sociais no Brasil.

Monteiro Lobato, em texto publicado em 1944, lembra o papel importante desempenhado por Casagrande \& senzala na nova visão sobre as ciências sociais brasileiras. "Seu livro era sociologia, jogava com toda a técnica da misteriosa ciência e com a sua estranha terminologia" (Lobato, [1944] 1991, p. IX). Almir de Andrade, no final dos anos de 1930, fazendo um balanço sobre as inovações culturais no Brasil afirma: "Se há movimento que marque de forma impressionante as novas tendências da cultura brasileira nestes últimos cinco anos, é, sem dú- 
vida aquele que se esboça no terreno da sociologia e que nos veio apresentar sob um aspecto novo o estudo da nossa realidade social. Foi Gilberto Freyre quem o iniciou" (Andrade, 1939, p. 35).

Esses e outros exemplos permitiram-me inferir que Casa-grande \& senzala, Sobrados e mucambos e Nordeste tiveram, nos anos de 1930 e início da década seguinte, uma recepção como obras sociológicas inovadoras. Esse dado autorizou-me a levantar as questões: se sua análise muda os rumos do pensamento sociológico, qual o papel de Gilberto Freyre na formação da sociologia brasileira? O que significa esse salto apontado pelos críticos de sua época?

O enfrentamento delas está contido no sentido atribuído à palavra formação ao formular a pergunta: significa pensar como se dá o processo de análise social no cenário histórico brasileiro. Outra vez o "tal paradigma uspiano". ${ }^{4}$ Assim, para explicar o sentido do avanço analítico operado por Gilberto Freyre recorri, adaptando ao pensamento sociológico, a tese de Antonio Candido ([1959] 1981). Este autor, ao descrever a formação da literatura brasileira, distingue manifestações literárias de literatura como um siste$m a$. Na passagem para a segunda fase assinala a presença de três elementos, necessariamente articulados: “a existência de um conjunto de produtores literários, mais ou menos conscientes do seu papel; um conjunto de receptores, formando os diferentes tipos de público, sem os quais a obra não vive; um mecanismo transmissor (de modo geral, uma linguagem, traduzida em estilos), que liga uns a outros" (Idem, p. 23). Considerando que há uma corrente ligando Gilberto Freyre à temática e às intenções dos autores que o precedem, nesse quadro que elemento o distingue dos outros? A resposta pareceu-me simples: a linguagem. Gilberto Freyre, diferentemente dos analistas anteriores, utiliza um discurso diverso daquele institucional empregado por eles, em geral de perfil jurídico, examinando principalmente a eficácia das instituições políticas e sua adequação ao perfil da sociedade. Ora, o desenho desse perfil exige um diagnóstico cuja definição requer mecanismos específicos, com os quais não contavam. A exceção é, sem dúvida, Oliveira Vianna, que busca examinar a constituição da sociedade brasileira em Populaçôes meridionais do Brasil, mas ainda aceitando princípios da sociobiologia, tendo como suporte elementos da psicologia social (Vianna, 1920). Não é por acaso que a polêmica principal desenvolvida em Casa-grande \& senzala é direcionada às teses desse autor. A nova linguagem é o discurso sociológico. ${ }^{5}$

Foram esses elementos que me autorizaram a afirmar que Gilberto Freyre ocupa um lugar especial no processo de sistematização da sociologia brasilei$\mathrm{ra}$, assinalando o fim das manifestações sociológicas e abrindo espaço para uma sociologia sistemática. É claro que se trata de uma formulação que só tem validade se validarmos o método empregado para chegar a ela. Ou ainda, faz-se necessário perguntar se a questão que se configura como ponto de partida para minha reflexão tem fundamento. Caso contrário, trata-se apenas de uma invenção. No meu caso, pode ter razão o comentador que afirma estar "persuadido de que os cientistas sociais inventam muita coisa"... Se for assim, deixam de ter lugar as razões que fundam a afirmação que faço: Gilberto Freyre é uma das figuras principais no processo de sistematização da sociologia brasileira. É óbvio que além dessas elenco muitas outras razões que sustentam o lugar especial que lhe é reservado nas reflexões dedicadas às interpretações do Brasil.

O caráter sociológico que acredito estar presente nas obras de Gilberto Freyre levou-me a tentar uma exposição que mantivesse a articulação de suas teses e, ao mesmo tempo, permitisse explicar o sentido de cada uma delas no conjunto de sua visão sobre o país. Em outras palavras, à trilogia explicativa interpenetração etnias/culturas, patriarcado e trópico busquei a correspondência explicativa. Esse movimento talvez justifique o didatismo da exposição, que o comentador considera "de alto valor", o que recebo como elogio e agradeço, embora desconfie que "ser didático" hoje não esteja muito em moda. É claro que quando buscamos explicitar nossas idéias nos expomos muito. É muito mais fácil colocar na obscuridade os elos que as prendem, é mais charmoso manter certo mistério... Infelizmente não sei dominar essa técnica.

Nos grandes livros de Gilberto Freyre os três elementos acima indicados aparecem correlacionados, cada um deles encontrando sua explicação na convergência com os outros dois. Seria possível in- 
dicar o vértice do triângulo? O próprio autor denominou Introdução à história da sociedade patriarcal no Brasil ao conjunto formado por Casa-grande \& senzala, Sobrados e mucambos e Ordem e progresso. Considerei, então, o patriarcalismo como centro de sua reflexão, tema presente nos três livros e, ainda, em Nordeste, texto que adicionei a esse conjunto.

Outra vez ousei afastar-me do debate que afirma estar na questão da articulação das etnias e culturas o eixo da interpretação de Gilberto. A ênfase dada à contribuição cultural das três raças formadoras na constituição da sociedade brasileira é, inegavelmente, um passo gigante em relação às interpretações anteriores. Talvez essa importância, aliada ao fato de negar a inferioridade das raças não brancas, tenha ajudado a obscurecer o tema que aponto como tese principal que preside o conjunto de suas obras, isto é, a afirmação do papel do patriarcado na construção desse amálgama racial e cultural. Desde o prefácio de Casa-grande \& senzala essa importância é assinalada: "A casa-grande venceu no Brasil a Igreja, nos impulsos que esta a princípio manifestou para ser a dona da terra. Vencido o jesuíta, o senhor de engenho ficou dominando a colônia quase sozinho. $\mathrm{O}$ verdadeiro dono do Brasil. Mais do que os vice-reis e os bispos" (Freyre, 1933, p. XXI).

O tema ganha desenvolvimento em Sobrados e mucambos, principalmente a partir dos acréscimos feitos à segunda edição, de 1951. Chamo a atenção para a Introdução, datada de 1949, em que o autor mostra a articulação dos elementos de sua tese e explicita seu método (ou métodos). É nela que rebate a crítica de Braudel sobre a validade da explicação - sociedade patriarcal - apenas a uma região do país. Assim, afirma a prioridade da forma sociológica dos acontecimentos e fatos sobre o conteúdo ou substância destes (Freyre, 1981, p. LXXXIII). ${ }^{6}$ Mostrando que em Simmel esses elementos têm caráter metafórico, Sérgio Buarque de Holanda, comentando essa introdução, havia apontado os limites do emprego do conceito patriarcalismo - que teria caráter apenas descritivo - em face da categoria patrimonialismo - esta de amplitude explicativa. Trata-se de tema largamente explorado na análise sociológica, reflexão apontada por Florestan Fernandes também no início dos anos de $1950 .^{7}$ Acei- tando a formulação, busco compreender os efeitos políticos da interpretação gilbertiana.

Creio que neste ponto se apóia a principal controvérsia do denominado "grupo uspiano" com Gilberto Freyre. Aliás, não apenas com ele, mas com Oliveira Vianna, Nestor Duarte e Fernando de Azevedo. Trata-se de questionar a unilateralidade da análise desses autores gerada pela "redução do macrocosmo social inerente à ordem estamental e de castas ao microcosmo social inerente à plantação ou ao engenho e à fazenda". Florestan propõe, assim, uma análise sociológica que mostra que "a economia de plantação faz parte de um contexto histórico estrutural, inclusivo e determinante; o problema central não consiste em explicar uma ou outro, mas ambos" (Fernandes, 1979, p. 36). Em outros termos, a análise proposta pelo sociólogo paulista leva em consideração simultaneamente o processo que explicita as relações sociais - o patrimonialismo - e $\mathrm{o}$ ator que induz essas relações - o patriarca.

Parece-me que a direção da formulação permite mostrar como as relações sociais geradas no seio do regime escravocrata se estendem à sociedade brasileira posteriormente à abolição. Ao referirse ao colapso do trabalho servil, Florestan Fernandes diz: "o fato mais importante, do ponto de vista sociológico, diz respeito à preservação dos papéis políticos das velhas elites. Elas orientaram o processo, no conjunto, de modo a resguardar, intocáveis, todas as suas atribuições fundamentais na estrutura de poder na sociedade" (Idem, p. 207).

Em textos anteriores, Florestan já apontara os limites do conceito patriarcalismo para dar conta, de modo abrangente, da formação social brasileira. Já citei a prova de sua livre-docência, de 1953. Logo no início, o autor mostra os limites teóricos de tal formulação. De um lado, afirma que a própria noção "família patriarcal" não é precisa quanto às conotações sociológicas. De outro, diz que lhe atribuir uma função econômica é ponto polêmico, pois associa à idéia da família patriarcal a representação de uma espécie de estrutura social básica do sistema econômico ou, ainda, sugere-se que este está subordinado à atuação de pressões e controles sociais concentrados nas mãos de um senhor e de seus apaniguados. Assim, desenvolve o tema mostrando a necessidade de pôr em evidência aspectos 
peculiares da situação histórica sendo que a ausência desse fator define o caráter antes descritivo do que explicativo da noção.

Em $A$ integração do negro na sociedade de classes, a argumentação encaminha-se a demonstrar que os padrões assimétricos das relações raciais entre negros e brancos no Brasil desnudam uma estrutura social fundada em elementos que impedem a invocação de direitos civis, políticos e sociais (e que, por suposto, não atinge somente os negros, mas todas as camadas subalternas). Em outros termos, tratase de uma sociedade onde vastos setores, não apenas os negros e mulatos, têm negado o acesso a relações sociais igualitárias: prevalecem as relações pessoais marcadas de um lado pelos privilégios, de outro pela submissão, lealdade e conformismo em face dos interesses dominantes. "Quanto mais o negro e o mulato se identifiquem com os ideais da personalidade democrática, concatenado em torno da figura do cidadão e dos direitos fundamentais da pessoa, tanto mais eles são incompreendidos, avaliados etnocentricamente e depreciados" (Fernandes, 1965, vol. 1, p. 229).

Embora pudesse levantar outros pontos importantes da argumentação de Florestan Fernandes sobre essa temática, quero lembrar uma questão que me parece curiosa no debate sociológico. Vários cientistas sociais brasileiros e mesmo alguns estrangeiros consideram que a polêmica do sociólogo paulista e seu grupo de pesquisadores com Gilberto Freyre reside principalmente na crítica à tese da democracia racial. Um dado parece-me curioso: o livro $A$ integração do negro na sociedade de classes, que tem 655 páginas (são 2 volumes), dedica pouco mais de 16 páginas à crítica do mito da democracia racial, aliás apontado anteriormente pelos movimentos negros, pelo Teatro Experimental do Negro e por vários autores, como, por exemplo, Clovis Moura. A tese da obra é mais abrangente: trata-se de compreender a maneira pela qual o mito da democracia racial funcionou como um dos elementos da manutenção, no Brasil, mesmo com o advento da República, de uma sociedade patrimonialista. Em outros termos, o mito da democracia racial constituiu-se em mais um fator de resguardo por parte das velhas elites, das suas atribuições fundamentais na estrutura de poder da sociedade. Por essa razão, são as críticas que os pesquisadores uspianos fazem sobre o patriarcalismo que, a meu ver, se definem como centrais em oposição à interpretação do Brasil feita por Gilberto Freyre.

No quadro geral da pesquisa sobre a sociedade escravocrata e o negro nos estados do Paraná, Santa Catarina e Rio Grande do Sul, desenvolvida pela cadeira de Sociologia I da FFLCH-USP, entre 1955 e 1960, o livro de Fernando Henrique Cardoso, Capitalismo e escravidão no Brasil meridional constitui-se no texto que toma como central o tema patrimonialismo. Reconstruindo o escravismo como sistema, mostra que são as características da sociedade, as relações patrimonialistas que permitem a coexistência de capitalismo e escravidão. Os capítulos quinto e sexto, principalmente, mostram a conexão entre a estrutura e a organização sociais e as possibilidades de ação social e política. Ou seja, a potencialidade de ação política dos setores populares é limitada (engessada?) pelo patrimonialismo (Cardoso, 1977). Nesse sentido, mesmo sem referência explícita, propõe explicação bem diferente daquela sugerida por Gilberto Freyre. Este, desde o título Casa-grande \& senzala, configura os termos das relações entre senhores e escravos. O \& que liga os dois extremos da dominação não só relativiza os opostos, representados pela expressão antagonismos em equilíbrio, como avança na direção de apontar uma alteração de conteúdo dos papéis sociais. ${ }^{8}$ Como aponta Gilberto, a presença "de dinâmica democratizante como corretivo à estabelecida hierarquia" (Freyre, 1968, p. 120).

Em Capitalismo e escravidão Cardoso mostra que a oposição dos dois sistemas torna-se possível pela mediação de uma sociedade caracterizada pelo patrimonialismo, onde coexistem novos e velhos modos de fundar as relações sociais. Uma forma que será denominada por Florestan Fernandes "polarizações dinâmicas".

Assim, contrapõem-se duas visões sobre a escravidão. A de Gilberto Freyre, apoiando-se em Alfred Zimmern, historiador da Grécia Antiga, encontra no escravo africano no Brasil as características civilizadoras presentes na configuração da cultura helênica via escravos. ${ }^{9}$ A de Fernando Henrique Cardoso refere-se à escravidão moderna e seu papel em uma outra formação econômico-social. 
Estou consciente de que a abordagem que faço da interpretação de Gilberto Freyre tem a ver com posições que assumo em relação à sociedade brasileira, perspectivas essas que se referem ao fato de analisá-la como marcada pelo patrimonialismo, sem dúvida a partir dessa tradição uspiana. Os possíveis equívocos cometidos em relação a essa tradição são de minha inteira responsabilidade.

Por caminhos diversos, Roberto Motta desenvolve o tema: é arriscado traduzir o pensamento de Gilberto Freyre, "feito à base de intuições e imagens", em "língua de universidade", podendo ocorrer uma hiper-racionalização das intuições ao tentar traduzi-las em conceitos. Assinalo, aqui, dois pontos, que não vou desenvolver. Discutindo a formação do pensamento sociológico, Nisbet mostra que as grandes idéias que o constituem - classe/status, comunidade/sociedade, autoridade/poder, para citar apenas algumas - são "resultado de processos de pensamento - imaginação, visão, intuição - que têm tanta relação com o artista como com o investigador científico" (Nisbet, 1977, p. 34). Por isso assinala que os grandes sociólogos "jamais deixaram de ser filósofos morais. E jamais deixaram de ser artistas!'. Estas características levam esses autores a trilhar o caminho de ida e volta: primeiramente a intuição, sua qualidade de artista, permite que dêem um salto em relação às posições que os precederam; em seguida devem voltar a construir passo a passo o caminho para demonstrar que sua intuição tem sentido. Não é sem fundamento que o símbolo do intelectual é Sísifo, condenado eternamente a subir a montanha carregando uma pedra que, chegando ao topo, rola outra vez, obrigando-o a buscá-la.

Parece-me que esse duplo caminho foi trilhado por Gilberto. Seu "estilo inconfundível" traduzido em seus grandes livros desaparece, segundo o comentador, em Sociologia, que se apresenta como um livro "marcadamente cartesiano". Creio que a mesma linguagem aparece, também, em Como e porque sou e não sou sociólogo. Não creio que seja coincidência que ambos constituam-se em explicações sobre os fundamentos de sua obra, além das razões que o levaram a escrevê-la.

Roberto Motta declara que o aparecimento de Sociologia é um mistério para ele, pois a origem do livro constitui problema. Creio que o trabalho de
Simone Meucci pode esclarecer perfeitamente o problema. Com base em uma pesquisa original, a autora confronta os programas de cursos ministrados por Gilberto tanto na Universidade do Distrito Federal, como nos de formação para o magistério e Faculdade de Direito, dados no Recife, e mostra a conexão daquelas aulas com a temática do livro citado (Meucci, 2006).

Volto, agora, a Mário de Andrade que, finalizando o poema com que iniciei este texto, diz: Eu sou trezentos, sou trezentos-e-cinquenta, / Mas um dia afinal eu toparei comigo...

Afirmo, não tive nunca a pretensão de "topar" com Gilberto, mas apenas assinalar um aspecto de Gilberto Freyre que minha perspectiva sociológica permitiu. Acredito que não exista uma só explicação que defina um autor. Se assim fosse, não teríamos a possibilidade de desenvolvimento não só das ciências sociais, como também da literatura, da história da arte, da filosofia etc., mas professaríamos uma religião.

Agradeço mais uma vez a atenção que Motta dedicou a meu livro, o que me permitiu tentar esclarecer alguns pontos que ficaram obscuros.

\section{Notas}

1 Tomo a liberdade de não desenvolver aqui o argumento remetendo a um texto em que fundamento essa posição (Bastos, 2002).

2 A frase é do prefácio da $1^{\text {a }}$ edição, de 1962.

3 No Capítulo 4 de Casa-grande \& senzala a discussão dos dois temas de forma correlacionada apóia-se em inúmeros autores, entre os quais figura Franz Boas.

4 Não vou discutir a questão e remeto o debate ao livro de Arantes e Arantes (1997).

5 Lembro ainda que a ampla recepção está ligada às políticas educacional e cultural adotadas pós-1930, que ampliaram o público receptor (cf. Candido, 1987, pp. 181-198).

6 Tive a oportunidade de desenvolver essa discussão, que envolve Gilberto Freyre e Sergio Buarque de Holanda, no texto "Raízes do Brasil - Sobrados e Mucambos: um diálogo" (2008).

7 Chamo a atenção para texto de Florestan Fernandes, na prova escrita do concurso de livre-docência para a cadeira de Sociologia I da Faculdade de Filosofia, 
Ciências e Letras da Universidade de São Paulo, realizada em 19/10/1953, cujo ponto sorteado foi "A família patriarcal e suas funções econômicas", onde esse tema é desenvolvido. Ver Revista USP, 29, São Paulo, 1996, pp. 74-81. "Compuseram a banca examinadora os professores Fernando de Azevedo, Roger Bastide, Herbert Baldus, Mário Wagner da Cunha e Octavio da Costa Eduardo. Gilberto Freyre, escolhido para compor a banca, enviou à Faculdade [...]" carta explicando a impossibilidade de sua participação. José de Souza Martins forneceu ao dossiê Florestan Fernandes publicado no número citado esses dados presentes no arquivo da FFLCH-USP.

8 Ricardo Benzaquen de Araújo (1994) mostra como a expressão "antagonismos em equilíbrio" é aplicada por Gilberto em relação a vários aspectos da sociedade brasileira.

9 Maria Lúcia Garcia (2005) mostra quanto a figura e as teses de Zimmern impressionaram Gilberto, a ponto de confundir uma conferência a que assistiu do historiador com um curso.

\section{BIBLIOGRAFIA}

ANDRADE, Almir de. (1939), Aspectos da cultura brasileira. Rio de Janeiro, Schmidt Editor.

ARANTES, Otilia Beatriz Fiori \& ARANTES, Paulo Eduardo. (1997), Sentido da formação. Rio de Janeiro, Paz e Terra.

ARAÚJO, Ricardo Benzaquen de. (1994), Guerra e Paz: Casa-grande \& senzala e a obra de Gilberto Freyre nos anos 30. Rio de Janeiro, Editora 34.

BASTOS, Elide Rugai. (2002), "Pensamento social da escola sociológica paulista", in Sergio Miceli (org.), O que ler na ciência social brasileira - 19702002, São Paulo, Sumaré, pp. 183-230.

. (2008), "Raízes do Brasil - Sobrados e mucambos: um diálogo", in Pedro Meira Monteiro e João Kennedy Eugênio (orgs.), Sérgio Buarque de Holanda: perspectivas, Campinas/ Rio de Janeiro, Editora da Unicamp/ Editora da UERJ, pp. 227-244.

CANDIDO, Antonio. (1987), "A Revolução de 1930 e a cultura", in A educação pela noite \&o outros ensaios, São Paulo, Ática, pp. 181-198.
. ([1959] 1981), Formação da literatura brasileira: momentos decisivos. 6 ed. Belo Horizonte, Itatiaia.

CARDOSO, Fernando Henrique. (1977), Capitalismo e escravidão no Brasil meridional: o negro na sociedade escravocrata do Rio Grande do Sul. 2 ed. Rio de Janeiro, Paz e Terra.

FERNANDES, Florestan. (1979), Circuito fechado. 2 ed. São Paulo, Hucitec, p. 36.

FERNANDES, Florestan. ([1962] 1976), Sociologia numa era de revolução social. 2 ed. Rio de Janeiro, Zahar Editores.

FREYRE, Gilberto. (1933), Casa-grande \& senzala: formação da familia brasileira sob o regimen de economia patriarchal. Rio de Janeiro, Maia \& Schmidt Ltda. . (1941), "Introdução", in

Região e tradição, Rio de Janeiro, José Olympio. . (1957), Sociologia: introdução ao estudo dos seus princípios. Tomo I, 2 ed. revista, aumentada e atualizada. Rio de Janeiro, José Olympio, 1957. (1968), Como e porque sou e não sou sociólogo. Brasília, Editora da Universidade de Brasília. - (1981), Sobrados e mucambos. Rio de Janeiro, José Olympio, 1981

JAMESON, Fredric. (1992), O inconsciente político: a narrativa como ato socialmente simbólico. Trad. de Valter Lellis Siqueira, rev. de trad. de Maria Elisa Cevasco. São Paulo, Ática.

LOBATO, Monteiro. ([1944] 1991), "Prefácio à $1^{\text {a }}$ edição", in Diogo de Mello Menezes, Gilberto Freyre. 2 ed., Recife, Fundação Joaquim Nabuco/ Massangana.

MEUCCI, Simone. (2006), Gilberto Freyre e a sociologia no Brasil: da sistematização à constituição do campo cientifico. Tese de doutorado, Campinas, Programa de Doutorado em Sociologia, IFCH, Unicamp.

NISBET, Robert. (1977), La formación del pensamiento sociológico 1. Buenos Aires, Amorrortu.

PALLARES-BURKE, Maria Lúcia Garcia. (2005), Gilberto Freyre : um vitoriano nos trópicos. São Paulo, Editora da Unesp.

VIANNA, Oliveira. (1920), Populações meridionais do Brasil: paulistas, fluminenses, mineiros. São Paulo, Monteiro Lobato e Cia. 